\title{
ADSORÇÃO COMPETITIVA DE INIBIDOR DE CORROSÃO USADO EM POÇOS DE PERFURAÇÃO DE PETRÓLEO SOBRE AÇO, ESMECTITA E ARENITO
}

\author{
Ingrid A. G. A. Souza e Denise F. S. Petri* \\ Instituto de Química, Universidade de São Paulo. Av. Prof. Lineu Prestes 748, 05508-900 São Paulo - SP, Brasil \\ João C. Queiroz Neto \\ Centro de Pesquisas e Desenvolvimento da Petrobras, Rio de Janeiro - RJ, Brasil
}

Recebido em 19/2/08; aceito em 10/7/08; publicado na web em 27/11/08

\begin{abstract}
COMPETITIVE ADSORPTION OF WELLBORES CORROSION INHIBITOR ONTO STEEL, ESMECTITE AND SANDSTONE. A commercial corrosion inhibitor used in petroleum production was characterized by means of infrared spectroscopy and energy dispersive spectroscopy (EDS). Predicting the adsorption behavior of corrosion inhibitor onto steel, sandstone and esmectite is the key to improve working conditions. In this study, the adsorption kinetics of inhibitor formulations in $\mathrm{HCl} 15 \%$ or in Mud $\mathrm{Acid}(\mathrm{HCl}$ $13,5 \%$ and ammonium bifluoride) onto steel, sandstone and esmectite was determined by means of spectrophotometry. Kinetic parameters indicated that adsorption of inhibitor in the presence of bifluoride was favored. Moreover, the adsorption constant rate was the largest when the substrate was esmectite.
\end{abstract}

Keywords: corrosion inhibitor; adsorption; acidification.

\section{INTRODUÇÃO}

Acidificação é uma técnica que tem sido usada extensivamente nos últimos 80 anos em poços de petróleo na dissolução de minerais, resíduos do fluido de perfuração e outros materiais presentes nos poros dessa rocha, visando com isso recuperar ou aumentar a produtividade ou injetividade. Essa acidificação consiste na injeção de um volume de uma solução ácida na rocha produtora ou injetora, usando uma pressão inferior à pressão de fratura da rocha. As formulações ácidas mais usadas são à base de ácido clorídrico $(\mathrm{HCl})$, ácidos orgânicos ou a mistura do $\mathrm{HCl}$ com bifluoreto de amônio ( $\left.\mathrm{NH}_{4} \mathrm{~F} . \mathrm{HF}\right)$, comumente chamada de $\mathrm{Mud}$ Acid. Essas formulações ácidas requerem sempre o uso de um inibidor de corrosão para evitar o desgaste prematuro do revestimento de produção pelo ataque ácido, ${ }^{1-6}$ bem como são adicionados também outros aditivos à formulação, cada um com finalidade específica, como descrito a seguir. O solvente mútuo (o mais usado é o butil glicol) reduz a adsorção do inibidor de corrosão sobre partículas de argila não-dissolvidas que estabilizam emulsões formadas entre a mistura ácida e o óleo da formação, aumenta a solubilidade e compatibilidade de inibidores e os quebradores de emulsão e outros aditivos, além de prevenir a inversão de molhabilidade sobre a superfície da rocha, que poderia reduzir a produtividade do poço. Seqüestradores de ferro previnem a precipitação de hidróxidos ferrosos e férricos, evitando a formação de borras por estes íons. Tensoativos não-iônicos são utilizados para estabilizar as emulsões e inibir a formação de borras. O inibidor de corrosão é escolhido de acordo com o tipo de ácido, temperatura de formação e características do metal. Um dos inibidores muito utilizado nas operações de exploração de petróleo é o ácido pentametilfosfônico dietilenotriamina (DETPMP), cuja estrutura química está representada na Figura 1S (material suplementar). ${ }^{1,2}$ Entretanto, produtos regionais modificados, como o óleo de coco saponificado, tem se mostrado eficientes como inibidores de corrosão.?

$\mathrm{O}$ arenito é o reservatório de petróleo mais comum nas bacias petroleiras brasileiras e quando se requer acidificá-los normalmente se

*e-mail: dfsp@iq.usp.br faz uso das formulações em $\mathrm{HCl} 15 \%$ ou do Mud Acid, Por outro lado, concluída a operação de acidificação o poço é colocado para produzir. Normalmente parte do volume de ácido usado na operação (ácido gasto) retorna junto com o óleo, gás e água ao iniciar a produção do poço. Entretanto, se tem observado que esse resíduo de ácido causa corrosão nas superfícies do revestimento de produção posicionado acima da zona acidificada. Este problema pode estar relacionado com a adsorção do inibidor de corrosão nas superfícies do arenito acidificado. Pois, quando o poço recém acidificado é colocado para produzir, o ácido gasto é produzido junto com o hidrocarboneto e a água de formação e passa a corroer as paredes do revestimento de produção na sua subida para a superfície. Por causa disso foi realizado um estudo, visando o entendimento desse processo e para tal, adotou-se a seguinte estratégia de pesquisa: caracterização química do inibidor de corrosão comercial; adsorção e dessorção das formulações ácidas de inibidor sobre arenito Marlim (principal rocha reservatório produtora da bacia de Campos), esmectita (um dos minerais mais comuns nas superfícies dos poros da rocha), aço tratado com $13 \mathrm{Cr}$ e sobre lâminas de $\mathrm{Si} / \mathrm{SiO}_{2}$ e, análises morfológica e de composição química do inibidor adsorvido sobre os diferentes substratos.

\section{PARTE EXPERIMENTAL}

\section{Materiais}

Ácido clorídrico $(\mathrm{HCl})$ p.a. foi fornecido pela Casa Americana, SP. Inibidor de corrosão, butilglicol, tensoativo neutro Ultrawet 70 (Oxiteno, SP), e bifluoreto de amônio foram concedidos pelo CENPES/Petrobras. Os substratos aço inox CR13 (2,0 cm x 0,6 cm x $0,4 \mathrm{~cm}$ ), esmectita triturada e arenito Marlim triturado foram obtidos em unidades operacionais da bacia de Campos. Lâminas de $\mathrm{Si} / \mathrm{SiO}_{2}$ $(1,0 \mathrm{~cm} \times 1,0 \mathrm{~cm})$ contendo camada nativa de $\mathrm{SiO}_{2}$ (com espessura de 2,0 \pm 0,2 nm) foram adquiridas da SiliconQuest (Santa Barbara, EUA). As lâminas de $\mathrm{Si} / \mathrm{SiO}_{2}$ foram usadas por serem superfícies ricas em sílica, como o arenito, e muito planas, permitindo a determinação da espessura de inibidor adsorvido por medidas elipsométricas.

As formulações ácidas de inibidor de corrosão com as quantidades 
de cada reagente para um volume final de $10 \mathrm{~mL}$ estão apresentadas na Tabela 1. As escolhas destes materiais com as respectivas quantidades foram feitas de modo a mimetizar as formulações ácidas geralmente utilizadas em operações de acidificação.

Tabela 1. Formulações ácidas de inibidor com as quantidades de cada reagente para o volume final de $10 \mathrm{~mL}$

\begin{tabular}{lccccc}
\hline & $\mathrm{HCl}$ & $\mathrm{HCl}$ & Ultrawet & Butilglicol inibidor \\
& $15 \%$ & $13,5 \%$ & 70 & \\
\hline $\begin{array}{l}\text { Formulação } \\
\mathrm{HCl} \mathrm{15 \%}\end{array}$ & $8,57 \mathrm{~mL}$ & - & $0,03 \mathrm{~mL}$ & $1 \mathrm{~mL}$ & $0,40 \mathrm{~mL}$ \\
$\begin{array}{l}\text { Formulação } \\
\text { HCl 13,5\%* ou }\end{array}$ & - & $8,57 \mathrm{~mL}$ & $0,03 \mathrm{~mL}$ & $1 \mathrm{~mL}$ & $0,40 \mathrm{~mL}$ \\
\begin{tabular}{l} 
Mud Acid \\
\hline
\end{tabular}
\end{tabular}

(*) A solução ácida com bifluoreto de amônio é preparada adicionando-se $24 \mathrm{~g}$ de $\mathrm{NH}_{4}$ F.HF por L de ácido clorídrico $15 \%$.

\section{Métodos}

Análises de espectroscopia vibracional no infravermelho com transformada de Fourier (FTIR) foram realizadas num equipamento Bohmen MB100 com resolução de $4 \mathrm{~cm}^{-1}$ para amostras do inibidor puro com o intuito de identificar a estrutura química de componentes orgânicos presentes no inibidor.

O comportamento de adsorção do inibidor dissolvido em $\mathrm{HCl}$ $15 \%$ sobre lâminas de $\mathrm{Si} / \mathrm{SiO}_{2}$ foi estudado através das medidas das espessuras das camadas adsorvidas em função da concentração do inibidor. As lâminas foram previamente limpas com acetona técnica, e secas com jatos de $\mathrm{N}_{2}$, e em seguida a espessura da camada de $\mathrm{SiO}_{2}$ foi determinada por elipsometria ${ }^{8-11}$ num equipamento DRE EL-X02 (Ratzeburg, Alemanha). A seguir, as lâminas foram inseridas nas soluções ácidas, permanecendo em contato durante $2 \mathrm{~h}$, a $60 \pm 2{ }^{\circ} \mathrm{C}$. Depois deste período, as lâminas foram lavadas com água destilada para retirar o material que estava fisicamente adsorvido e secas com jatos de $\mathrm{N}_{2}$. Todos os ensaios foram realizados em duplicatas. As espessuras (d) das camadas adsorvidas foram determinadas por elipsometria, ${ }^{8}$ usando o valor de 1,500 para o índice de refração da camada adsorvida. Este é um valor comumente encontrado para moléculas orgânicas no comprimento de onda de $633 \mathrm{~nm}$, o qual foi usado para as medidas elipsométricas. ${ }^{12}$ Detalhes sobre elipsometria e os modelos aqui adotados podem ser encontrados em diversas referências. ${ }^{8-10}$ A composição da camada adsorvida foi também analisada por microscopia eletrônica de varredura (MEV) e por análise de energia dispersiva (EDS) num equipamento Jeol 7401-F. Foram feitos ensaios de adsorção das formulações $\mathrm{HCl} 15 \%$ e $\mathrm{HCl}$ 13,5\%, sobre lâminas de $\mathrm{Si} / \mathrm{SiO}_{2}$ e aço, mas as superfícies das camadas adsorvidas sobre aço apresentaram alta rugosidade impedindo a realização de medidas elipsométricas. Como o princípio da elipsometria está baseado em luz refletida a partir de uma superfície planar refletora, esmectita e arenito triturados não são superfícies adequadas para a técnica, devido ao alto espalhamento e falta de planaridade.

Estudo espectrofotométrico sobre a cinética de adsorção das formulações $\mathrm{HCl} 15 \%$ e $\mathrm{HCl}$ 13,5\% sobre aço, arenito e esmectita foi realizado a $60 \pm 2{ }^{\circ} \mathrm{C}$, considerando os períodos de tempo de interação de $10,20,30,45,60,90$, e $120 \mathrm{~min}$. No caso do aço, as peças foram imersas nas formulações e após o período de interação, retirou-se o sobrenadante, que foi diluído 100 vezes para medidas de absorbância na faixa de 380 a $700 \mathrm{~nm}$, num espectrofotômetro Beckmann-Coulter DU 600. No caso do arenito e esmectita, $5 \mathrm{~g}$ de substrato foram imersos em $100 \mathrm{~mL}$ de formulação. Após o período de interação, retirou-se o sobrenadante, que foi centrifugado (10.000 rpm durante
20 min) e diluído 100 vezes para medidas espectrofotométricas. Após a adsorção, os substratos foram lavados com água destilada para remover substâncias que poderiam estar somente fisicamente adsorvidas, secos com jatos de $\mathrm{N}_{2}$ e analisados por MEV-EDS.

\section{RESULTADOS E DISCUSSÃO}

\section{Caracterização do inibidor de corrosão}

A Figura 1 mostra o espectro FTIR obtido para amostra do inibidor comercial. A tentativa de atribuição de bandas ${ }^{13}$ indica que um dos componentes da formulação do inibidor é possivelmente o ácido pentametilfosfônico dietilenotriamina (DETPMP), comumente utilizado como inibidor em operações de exploração de petróleo: deformação axial de O-H (larga), 3.700-3.100 cm ${ }^{-1}$; deformação axial de C-H, 2926, $2869 \mathrm{~cm}^{-1}$; deformação angular simétrica de $\mathrm{N}-\mathrm{H}, 1675 \mathrm{~cm}^{-1}$; deformação angular simétrica de $\mathrm{C}-\mathrm{H}, 1455 \mathrm{~cm}^{-1}$, deformação axial de $\mathrm{P}=\mathrm{O}, 1150 \mathrm{~cm}^{-1}$; deformação axial de C-N, 1104 $\mathrm{cm}^{-1}$; deformação axial de P-OH, 1040-910 $\mathrm{cm}^{-1}$, deformação axial de P-O-P, 1000-870 $\mathrm{cm}^{-1}$; deformação angular assimétrica de $\mathrm{C}-\mathrm{H}$, $733 \mathrm{~cm}^{-1}$. Adicionalmente nota-se a presença de uma banda de média intensidade em $1723 \mathrm{~cm}^{-1}$, a qual poderia ser atribuída à deformação axial de $\mathrm{C}=\mathrm{O}$. Neste caso, a presença da carbonila sugere que além do DETPMP, o inibidor pode conter ácidos ou ésteres orgânicos e aminas primárias ou secundárias. A presença de espécies inorgânicas na composição do inibidor foi verificada por análises de EDS, como descrito a seguir.

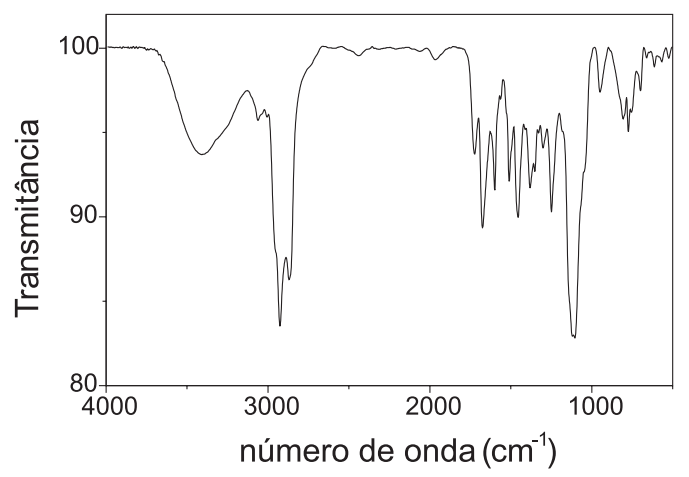

Figura 1. Espectro FTIR obtido para amostra do inibidor de corrosão

A espessura média da camada de inibidor de corrosão adsorvido sobre lâminas de $\mathrm{Si} / \mathrm{SiO}_{2}$ aumentou exponencialmente com a concentração (v/v \%) de inibidor na solução, como mostra a Figura 2S. O melhor ajuste dos pontos experimentais foi obtido com a equação $\mathrm{y}=1,6342 \mathrm{e}^{(\mathrm{x} / 1,2145)}$, onde $\mathrm{x}$ é a concentração (v/v \%) de inibidor. Este comportamento é típico de adsorção em multicamadas. Micrografias eletrônicas de varredura obtidas para camadas de inibidor de $40 \mathrm{~nm}$ de espessura sobre lâminas de $\mathrm{Si} / \mathrm{SiO}_{2}$ mostram a presença de placas orientadas formando ângulo de aproximadamente $60^{\circ}$ entre si, como mostra a Figura 3S. Análises de EDS obtidas para diferentes regiões da camada de inibidor indicaram a presença predominante do elemento cobre e traços de Si (Figura 4S). O sinal do Si é proveniente da lâmina sobre a qual o inibidor adsorveu. A detecção de $\mathrm{Cu}$ sugere que o inibidor contenha complexos formados entre os átomos de $\mathrm{N}$ do DETPMP e íons cobre. Além disso, ligações de hidrogênio entre as hidroxilas do DETPMP e os grupos silanóis das superfícies das lâminas de $\mathrm{Si} / \mathrm{SiO}_{2}$ e do arenito favorecem a adsorção. Assim, os complexos formados por DETPMP e cobre podem adsorver paralelamente à superfície de $\mathrm{Si} / \mathrm{SiO}_{2}$ formando uma primeira camada, sobre a qual adsorvem as próximas moléculas de complexos, formando assim 
multicamadas orientadas, evidenciadas pelas medidas de elipsometria e imagens de MEV.

\section{Adsorção das formulações HCl 15\% e HCl 13,5\% sobre aço, arenito e esmectita}

As cinéticas de adsorção das formulações $\mathrm{HCl} 15 \%$ e $\mathrm{HCl}$ 13,5\% sobre aço, arenito e esmectita foram obtidas a partir de medidas de absorbância. Os espectros de absorbância na faixa de 380 a $700 \mathrm{~nm}$ obtidos para as soluções sobrenadantes (diluídos 100 vezes) depois da adsorção das formulações $\mathrm{HCl} 15 \%$ e $\mathrm{HCl} 13,5 \%$ sobre arenito estão apresentados nas Figuras 5S e 6S, respectivamente. Estes espectros são similares àqueles obtidos para as soluções sobrenadantes depois da adsorção das formulações $\mathrm{HCl} 15 \%$ e $\mathrm{HCl} 13,5 \%$ sobre esmectita ou aço. Observou-se um máximo de absorbância em 422 nm (transição eletrônica típica de metal de transição com transferência de carga d- $\left.\pi^{*}\right),{ }^{15}$ seguido de um decaimento contínuo com o aumento do comprimento de onda. Para obtenção do percentual de adsorção (Ads\%) do inibidor sobre o substrato, foram determinadas as absorbâncias em $422 \mathrm{~nm}\left(\mathrm{Abs}^{422}\right)$. O valor de $\mathrm{Abs}^{422}$ para o inibidor sem interagir com o substrato $(0 \mathrm{~min}=100 \%)$ foi tomado como valor máximo $(0$ $\min =100 \%$ ) e Ads igual a $0 \%$, porque todo o inibidor está livre em solução. Considerando que os sistemas seguem a lei de Beer-Lambert, as absorbâncias lidas para os diferentes tempos de adsorção são diretamente proporcionais ao valor máximo, permitindo calcular o percentual de inibidor que não adsorveu, ou seja, qual percentagem de inibidor está livre na solução. Subtraindo $100 \%$ do percentual de inibidor livre determina-se o percentual adsorvido (Ads\%).

As cinéticas de adsorção das formulações de inibidor de corrosão $\mathrm{HCl} 15 \%$ e $\mathrm{HCl} 13,5 \%$ sobre aço, arenito e esmectita estão apresentadas nas Figuras 2, 3 e 4, respectivamente. Os dados experimentais foram ajustados com a equação Ads $(\mathrm{t})=\mathrm{Ads}_{\mathrm{eq}}-\mathrm{k} \mathrm{e}^{-(\text {t/teq) }}$, onde $\mathrm{Ads}_{\mathrm{eq}}$ é o percentual de adsorção do inibidor sobre o substrato no equilíbrio, $\mathrm{k}$ é a constante da velocidade da adsorção e $\mathrm{t}_{\mathrm{eq}}$ é o tempo necessário para que o platô de equilíbrio seja atingido. ${ }^{16}$ Os parâmetros cinéticos obtidos a partir dos ajustes estão apresentados na Tabela 2. A Figura 2 apresenta as cinéticas de adsorção das formulações de inibidor de corrosão $\mathrm{HCl} 15 \%$ e $\mathrm{HCl} 13,5 \%$ sobre aço. No caso da formulação $\mathrm{HCl}$ $15 \%$ o equilíbrio de adsorção é atingido após 17,9 min com $60,0 \%$ de adsorção de inibidor. A percentagem de adsorção aumenta para 90,9\% quando o bifluoreto de amônio está presente na formulação, porém o equilíbrio de adsorção só foi atingido após 26 min. O aumento da adsorção do inibidor na presença do bifluoreto pode ser devido à formação de fluoreto de Fe (II), a qual ativaria a superfície para a ancoragem das moléculas de DETPMP. Imagens de MEV e análises de EDS foram obtidas para o material adsorvido sobre superfícies de aço, após 30 e $60 \mathrm{~min}$, que estiveram em contato com formulações $\mathrm{HCl} 15 \%$ e $\mathrm{HCl} 13,5 \%$. De forma geral, não foi observada influência significativa do tempo de adsorção e do tipo de formulação sobre as morfologias e composições químicas obtidas. A Figura 5 mostra imagens típicas de MEV da formulação $\mathrm{HCl}$ 15\% adsorvida sobre aço, as quais evidenciam estrutura irregular e esponjosa da camada adsorvida. As análises de EDS (Figura 7S) mostram a presença dos elementos Fe (0,60 keV, 6,4 keV), Cr (0,571 keV) e Cu $(0,928 \mathrm{keV}$ e 8,041 keV), independentemente de ter adsorvido formulação $\mathrm{HCl}$ $15 \%$ ou $\mathrm{HCl} 13,5 \%$ sobre aço. Fe e $\mathrm{Cr}$ são provenientes do aço e $\mathrm{Cu}$ é oriundo do inibidor adsorvido. A identificação de flúor neste caso é difícil de ser feita, pois o Fe é interferente do F (0,677 keV).

As cinéticas de adsorção das formulações de inibidor de corrosão $\mathrm{HCl} 15 \%$ e $\mathrm{HCl} 13,5 \%$ sobre arenito estão apresentadas na Figura 3. No caso da formulação $\mathrm{HCl} 15 \%$ o equilíbrio de adsorção é atingido após 45,7 min com $42,8 \%$ de adsorção de inibidor. A presença do bifluoreto de amônio na formulação elevou a percentagem de adsorção

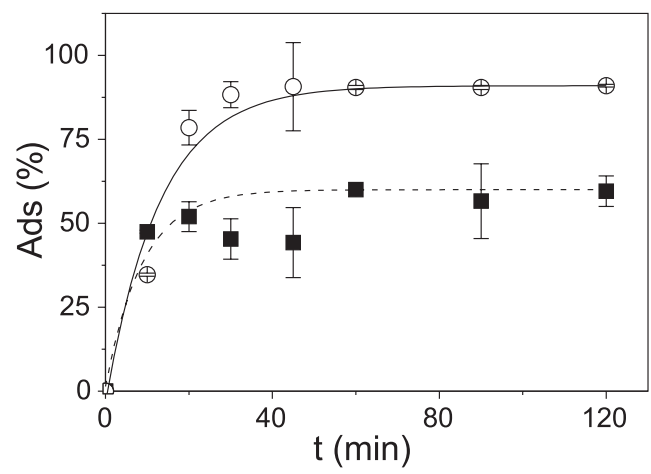

Figura 2. Cinética de adsorção das formulações de inibidor de corrosão $\mathrm{HCl} 15 \%$ quadrado) e $\mathrm{HCl} 13,5 \%$ (círculo) sobre aço. As linhas pontilhada e sólida correspondem aos respectivos ajustes exponenciais

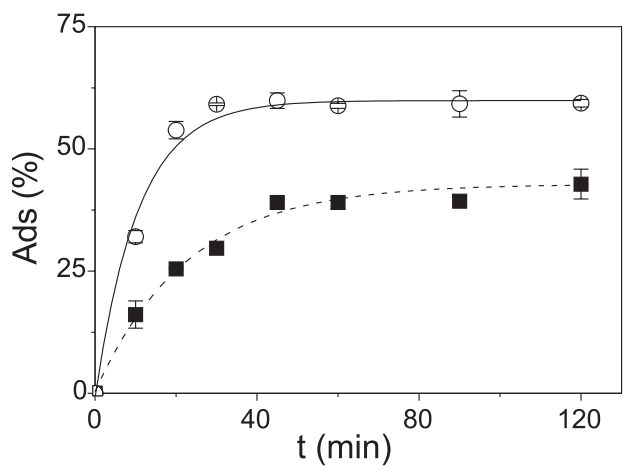

Figura 3. Cinética de adsorção das formulações de inibidor de corrosão $\mathrm{HCl}$ $15 \%$ quadrado) e $\mathrm{HCl}$ 13,5\% (círculo) sobre arenito. As linhas pontilhada e sólida correspondem aos respectivos ajustes exponenciais

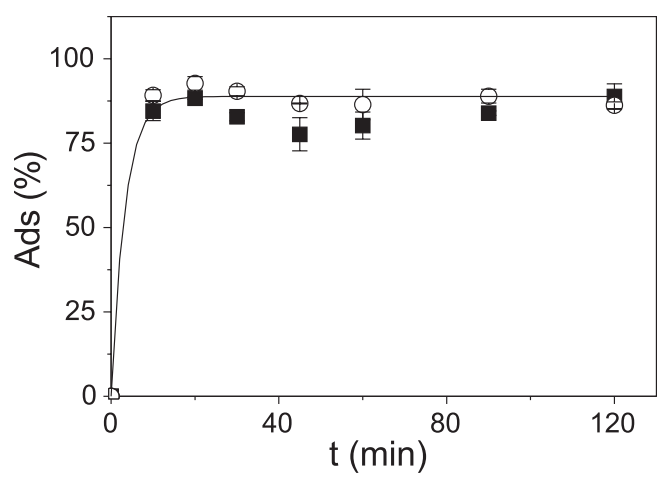

Figura 4. Cinética de adsorção das formulações de inibidor de corrosão $\mathrm{HCl}$ $15 \%$ quadrado) e $\mathrm{HCl} 13,5 \%$ (círculo) sobre esmectita. As linhas pontilhada e sólida correspondem aos respectivos ajustes exponenciais

para 59,9\% com equilíbrio de adsorção sendo atingido em apenas 21,4 min. O aumento da eficiência de adsorção pode ser explicado pela reação do bifluoreto de amônio com a sílica do arenito, onde há a formação do ácido fluorsilícico em duas etapas: ${ }^{4}$

$\mathrm{SiO}_{2}+4 \mathrm{HF} \rightarrow \mathrm{SiF}_{4}+2 \mathrm{H}_{2} \mathrm{O}$

$\mathrm{SiF}_{4}+2 \mathrm{HF} \rightarrow \mathrm{H}_{2} \mathrm{SiF}_{6}$

Imagens de MEV obtidas para formulações de inibidor de corrosão $\mathrm{HCl} 15 \%$ e $\mathrm{HCl} 13,5 \%$ adsorvidas durante 10 min sobre arenito estão 


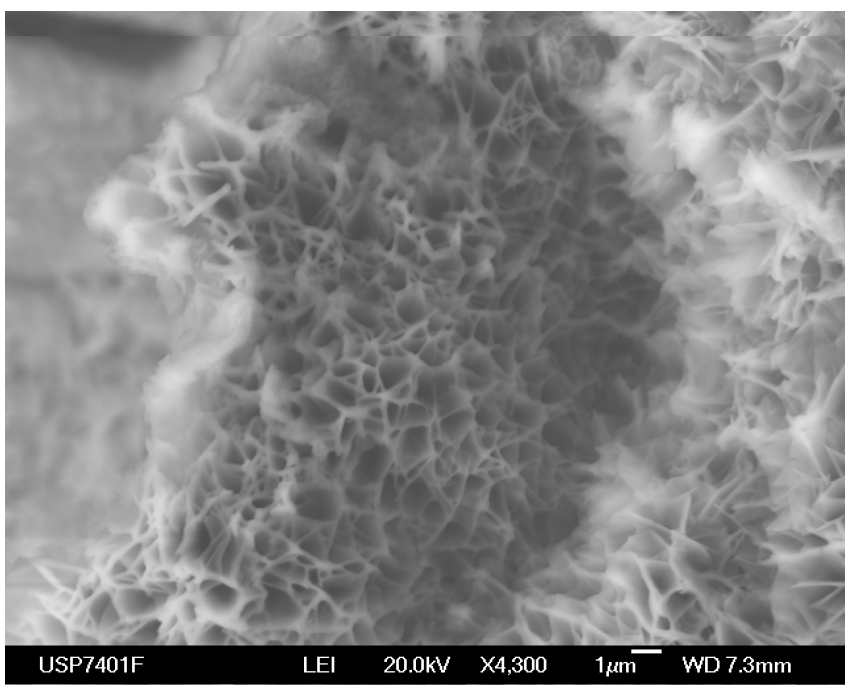

Figura 5. Típica imagem de MEV obtida para formulação $\mathrm{HCl} 15 \%$ adsorvida sobre aço

apresentadas na Figura 8S e Figura 6, respectivamente. Elas mostram estruturas geométricas de grandes dimensões atribuídas ao próprio arenito. Entretanto, na Figura 6 (formulação $\mathrm{HCl} \mathrm{13,5 \% )} \mathrm{há} \mathrm{estruturas}$ menores cúbicas e poligonais (tamanho médio de cada face é de $2 \mu \mathrm{m}$ ) adsorvidas sobre o arenito. Estas estruturas contribuem para aumentar os valores de Ads\% e podem ser atribuídas à formação do ácido fluorsilícico e de seus sais $\left(\mathrm{K}_{2} \mathrm{SiF}_{6}, \mathrm{Na}_{2} \mathrm{SiF}_{6}\right)$. Análises de EDS (Figura 9S) obtidas para as formulações de inibidor de corrosão $\mathrm{HCl} \mathrm{13,5 \%}$ adsorvidas sobre arenito evidenciaram o predomínio dos elementos $\mathrm{F}$ $(0,677 \mathrm{keV}), \mathrm{Si}(1,73 \mathrm{keV})$ e O $(0,523 \mathrm{keV})$. Observa-se também a presença de $\mathrm{Na}$, $\mathrm{K}$ e $\mathrm{Al}$ provenientes do arenito e ausência de $\mathrm{Cu}$. A razão para isto pode ser a baixa concentração de íons $\mathrm{Cu}$ adsorvidos, uma vez que esta amostra corresponde a 10 min de adsorção. Os elementos Si e O são característicos do arenito, mas o F não, indicando que ácido fluorsilícico e seus sais estão fortemente adsorvidos sobre o arenito. Portanto, o arenito compete com o aço pela adsorção da formulação $\mathrm{HCl}$ 13,5\%. As análises de EDS obtidas para as formulações de inibidor de corrosão $\mathrm{HCl} 15 \%$ adsorvidas sobre arenito apresentaram composição química semelhante àquela do Figura $9 \mathrm{~S}$, com o único diferencial sendo a ausência do pico relativo ao elemento flúor.

Comparando os parâmetros das cinéticas de adsorção das formulações de inibidor de corrosão $\mathrm{HCl} 15 \%$ e $\mathrm{HCl}$ 13,5\% sobre aço (Figura 2) e arenito (Figura 3), com aquelas observadas sobre esmectita (Figura 4) nota-se que a adsorção sobre esmectita e aço são as mais rápidas, pois apresentam as maiores constantes de velocidade (Tabela 2). No caso da esmectita, independentemente da presença do bifluoreto de amônio observa-se $90 \%$ de adsorção do inibidor já após 6,6 min. Esmectitas são argilas formadas por duas camadas

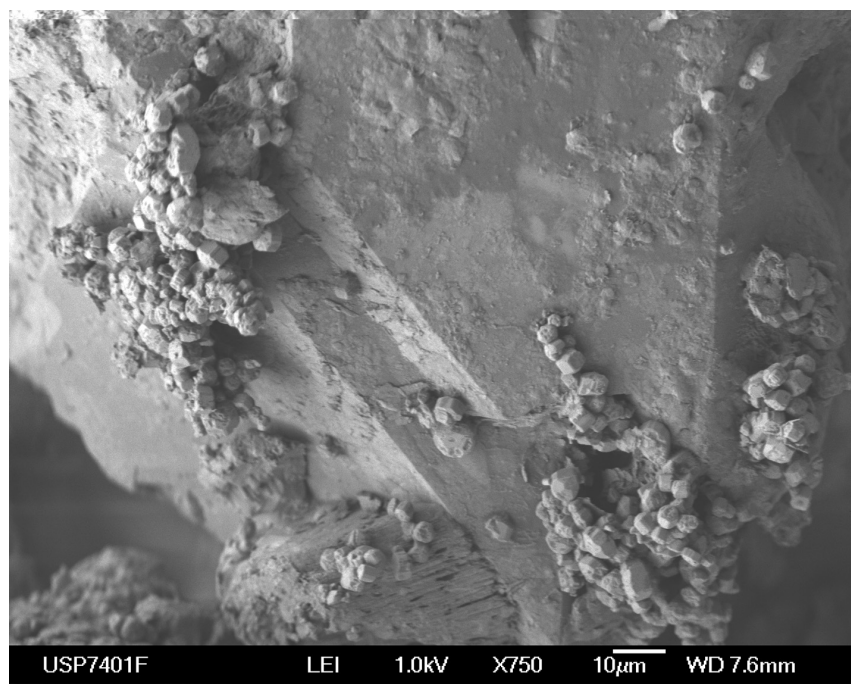

Figura 6. Típica imagem de MEV obtida para formulações $\mathrm{HCl} 13,5 \%$ adsorvidas sobre arenito durante $10 \mathrm{~min}$

tetraédricas contendo normalmente silício, alumínio e ferro (III), que envolvem uma camada octaédrica contendo alumínio, magnésio, ferro (II e III), além de outros elementos. ${ }^{17}$ A maior concentração de íons inorgânicos reativos em meio ácido provavelmente favorece a adsorção das formulações de inibidor sobre esmectita. É interessante observar que mesmo quando há íons de alumínio em abundância no meio, as reações com $\mathrm{HF}$ geram não só as espécies $\mathrm{SiF}_{4} \mathrm{e}_{2} \mathrm{SiF}_{6}$, mas também $\mathrm{AlF}_{2}^{+}$, 4,17 a presença do bifluoreto de amônio não exerceu nenhum efeito na eficiência de adsorção do inibidor sobre esmectita (Figura 4). Entretanto, as camadas adsorvidas na ausência (Figura 10S) e presença (Figura 7) de bifluoreto apresentaram morfologias bem distintas. Nas formulações $\mathrm{HCl}$ 15\% (Figura 10S), o inibidor adsorve formando camadas irregulares e amorfas, enquanto que nas formulações $\mathrm{HCl}$ 13,5\% (Figura 7) observa-se estruturas cúbicas e poligonais semelhantes àquelas observadas na Figura 6. Estes resultados mostram que estas estruturas geométricas são provavelmente sais de fluoreto. Recentemente, ${ }^{18}$ estruturas geométricas também foram observadas para DETPMP na presença de íons $\mathrm{Ba}^{2+}$, que atuaram como agentes quelantes. As morfologias variaram de flores a elipsóides e esferas, dependendo da concentração de DETPMP e pH. Entretanto, cubos e polígonos não foram observados.

As análises de EDS obtidas para formulações de inibidor de corrosão $\mathrm{HCl}$ 13,5\% (Figura 11S) adsorvidas sobre esmectita revelam o predomínio de $\mathrm{Al}, \mathrm{O}, \mathrm{Na}, \mathrm{Fe}$ e $\mathrm{Cu}$. A presença de $\mathrm{Cu}$ deve-se ao inibidor adsorvido, enquanto os outros elementos são os componentes da esmectita propriamente dita. Os sinais provenientes do Fe, F e O estão sobrepostos. Espectro de EDS semelhante ao da Figura 9S foi obtido para formulações de inibidor de corrosão $\mathrm{HCl} 15 \%$ adsorvidas

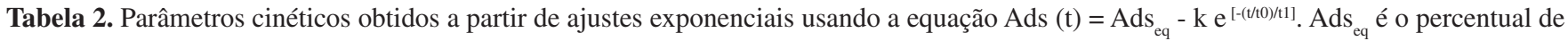
adsorção do inibidor sobre o substrato no equlíbrio, $\mathrm{k}$ é a constante da velocidade da adsorção e $\mathrm{t}_{1}$ é o tempo necessário para que o plateau de equilíbrio seja atingido

\begin{tabular}{lcccc}
\hline Substrato & formulação & Ads $_{\mathrm{eq}}(\%)$ & $\mathrm{k}\left(\mathrm{min}^{-1}\right)$ & $\mathrm{t}(\mathrm{min})$ \\
\hline Aço & $\mathrm{HCl} \mathrm{15 \%}$ & 60,0 & 58,57 & 17,9 \\
Aço & $\mathrm{HCl} \mathrm{13,5 \%}$ & 90,9 & 94,35 & 26,0 \\
Arenito & $\mathrm{HCl} \mathrm{15 \%}$ & 42,8 & 42,45 & 45,7 \\
Arenito & $\mathrm{HCl} \mathrm{13,5 \%}$ & 59,9 & 60,75 & 21,4 \\
Esmectita & $\mathrm{HCl} \mathrm{15 \%} \mathrm{ou} \mathrm{HCl} \mathrm{13,5 \%}$ & 88,9 & 88,85 & 6,6 \\
\hline
\end{tabular}




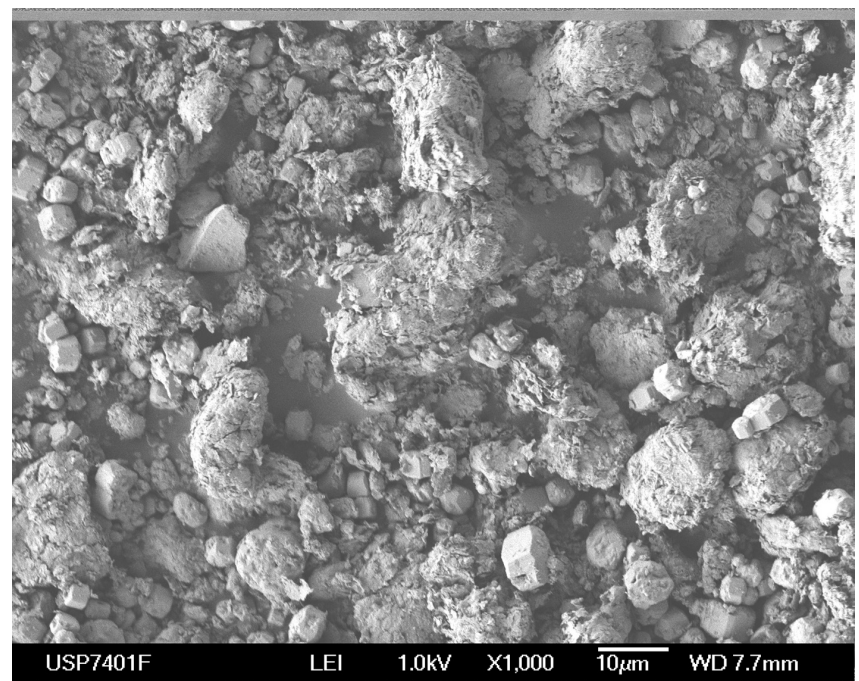

Figura 7. Típica imagem de MEV obtida para formulações $\mathrm{HCl} 13,5 \%$ adsorvidas sobre esmectita durante $10 \mathrm{~min}$

sobre esmectita.

Estes resultados não levaram em conta a área superficial de cada um dos substratos, que certamente é um fator muito importante no comportamento da adsorção em geral. Porém, mostram uma tendência clara de que na situação real de exploração de petróleo há forte competição entre aço, arenito e esmectita pelo inibidor de corrosão, sendo que a adsorção do inibidor sobre esmectita é mais rápida. Como conseqüência, parte do inibidor que deveria proteger o aço está adsorvida sobre arenito e esmectita (predominantemente). Como a quantidade efetiva de inibidor é menor que a necessária, ocorre a corrosão das paredes do revestimento de produção na subida do hidrocarboneto acidificado para a superfície. Para efeitos operacionais, maiores concentrações de inibidor nas formulações compensariam os efeitos da adsorção competitiva do mesmo sobre esmectita e arenito.

\section{CONCLUSÕES}

O inibidor de corrosão comercial parece ser composto por DETPMP, íons cobre e ácidos ou ésteres orgânicos. Os parâmetros cinéticos obtidos para adsorção das formulações $\mathrm{HCl} 15 \%$ e $\mathrm{HCl}$ $13,5 \%$ sobre aço, arenito e esmectita indicaram que a presença do bifluoreto de amônio em geral favorece a adsorção devido à ativação da superfície pela formação de compostos fluoretados e, sobre esmectita a adsorção é mais rápida. A adsorção competitiva do inibidor sobre os diferentes substratos é um fator que deve ser considerado nas formulações utilizadas em operações de exploração de petróleo. Assim sendo, parte do inibidor que deveria proteger o aço adsorve sobre o arenito e principalmente na esmectita. Em conseqüência disso, a quantidade efetiva de inibidor presente no ácido gasto é menor que a necessária, o que pode causar a corrosão das paredes do revestimento de produção quando o hidrocarboneto acidificado sobe para a superfície. Os efeitos de adsorção competitiva do inibidor sobre aço, esmectita e arenito podem ser compensados pelo uso de formulações, onde a concentração de inibidor seja maior que $4 \%$ (v/v).

\section{MATERIAL SUPLEMENTAR}

As Figuras identificadas como $\mathrm{S}$ ao longo do texto estão disponíveis gratuitamente em http://quimicanova.sbq.org.br, na forma de arquivo PDF.

\section{AGRADECIMENTOS}

D. F. S. Petri agradece à FAPESP e ao CNPq pelo auxílio financeiro.

\section{REFERÊNCIAS}

1. Gdanski, R.; Funkhauser, G. P.; Anais do SPE Formation Damage, Scheveningen, The Netherlands, 2005.

2. Sorbie, K. S.; Herriot-Watt, U.; Gdanski, R.; Anais do SPE International Symposium on Oilfiled Scale, Aberdeen, U.K., 2005.

3. Cardoso, S. P.; Reis, F. A.; Massapust, F. C.; Costa, J. F.; Tebaldi, L. S.; Araújo, L. F. L.; Silva, M. V. A.; Oliveira, T. S.; Gomes, J. A. C. P.; Hollauer, E.; Quim. Nova 2005, 28, 756.

4. Economides, M. J.; Hill, A. D.; Ehlig-Economides, C.; Petroleum Production Systems, Prentice-Hall Inc., PTR Prentice Hall: New Jersey, 1994.

5. Williams, B. B.; Gidley, J. L.; Schechter, R. S.; Acidizing Fundamentals, Society of Petroleum Engineers of AIME: USA, 1979

6. Taylor, K. C.; Nasr-El-Din, H. A.; Dajani, R. B.; J. Petroleum Sci. Eng. 2000, 28, 33 .

7. Rossi, C. G. F. T.; Scatena Jr., H.; Maciel, M. A. M.; Dantas, T. N. C.; Quim. Nova 2007, 30, 1128.

8. Azzam, R. M. A.; Bashara, N. M.; Ellipsometry and Polarized Light, North Holland Publication: Amsterdam, 1987.

9. Gonçalves, D.; Irene, E. A.; Quim Nova 2002, 25, 794.

10. Fujimoto, J.; Reis, E. A. O.; Campana Filho, S. P.; Petri, D. F. S.; Quim. Nova 2002, 25, 757.

11. Queiroz Neto, J. C.; Biscaia Jr., E. C.; Petri, D. F. S.; Quim. Nova 2007, 30, 909.

12. Palik, E. G.; Handbook of optical constants of solids, Academic Press Inc.: Londres, 1985.

13. Silverstein, R. M.; Webster, F. X.; Identificação espectrométrica de compostos orgânicos, $6^{\text {a }}$ ed., LTC Editora S.A.: Rio de Janeiro, 2000.

14. Bouffard, S. P.; Katon, J. E.; Sommer, A. J.; Danlelson, N. D.; Anal. Chem. 1994, 66, 1937.

15. Blaskie, M. W.; McMillin, D. R.; Inorg. Chem. 1980, 19, 3519.

16. Gdanski, R.; $12^{\text {th }}$ International Oil field Chemistry Symposium, Fagernes, Noruega, 2001.

17. Leite, S. Q. M.; Dieguezb, L. C.; San-Gil, R. A. S.; Menezes S. M. C.; Quim. Nova 2000, 23, 150 .

18. Xu, F. W. G.; Zhang, Z.; Song, S.; Dong, S.; J. Colloid Interface Sci. 2006, 293, 394. 


\section{ADSORÇÃO COMPETITIVA DE INIBIDOR DE CORROSÃO USADO EM POÇOS DE PERFURAÇÃO DE PETRÓLEO SOBRE AÇO, ESMECTITA E ARENITO}

Ingrid A. G. A. Souza e Denise F. S. Petri*

Instituto de Química, Universidade de São Paulo. Av. Prof. Lineu Prestes 748, 05508-900 São Paulo - SP, Brasil

João C. Queiroz Neto

Centro de Pesquisas e Desenvolvimento da Petrobras, Rio de Janeiro - RJ, Brasil

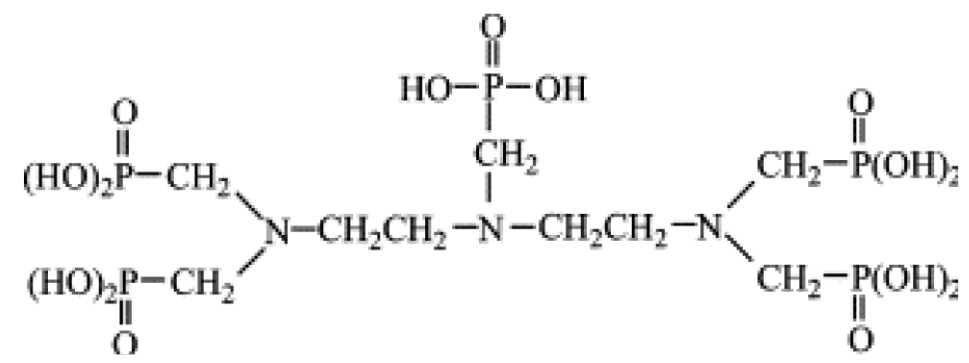

Figura 1S. Representação da estrutura química do ácido pentametilfosfônico dietilenotriamina (DETPMP)

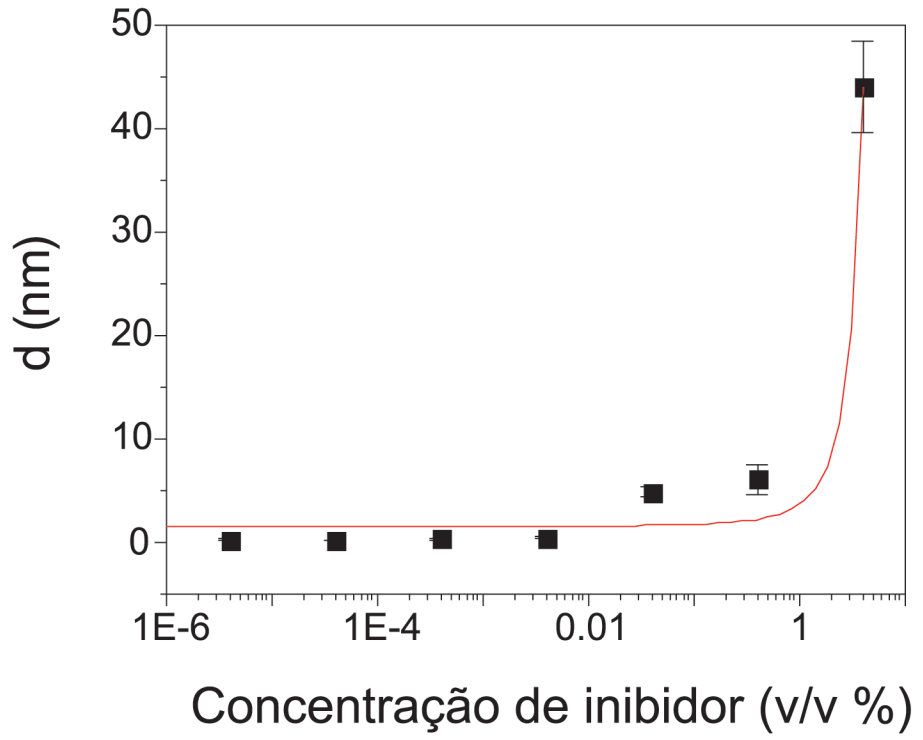

Figura 2S. Espessura média da camada de inibidor de corrosão adsorvido sobre lâminas de $\mathrm{Si} / \mathrm{SiO}{ }_{2}$ em função da concentração de inibidor após 2 h de adsorção a $60 \pm 2{ }^{\circ} \mathrm{C}$. As soluções foram preparadas em $\mathrm{HCl} 15 \%(\mathrm{v} / \mathrm{v})$. A linha vermelha corresponde ao ajuste dos pontos experimentais com a equação y $=1,6342 \mathrm{e}$ $(x /, 2145)$, onde $x$ é a concentração $(v / v \%)$ de inibidor na solução 


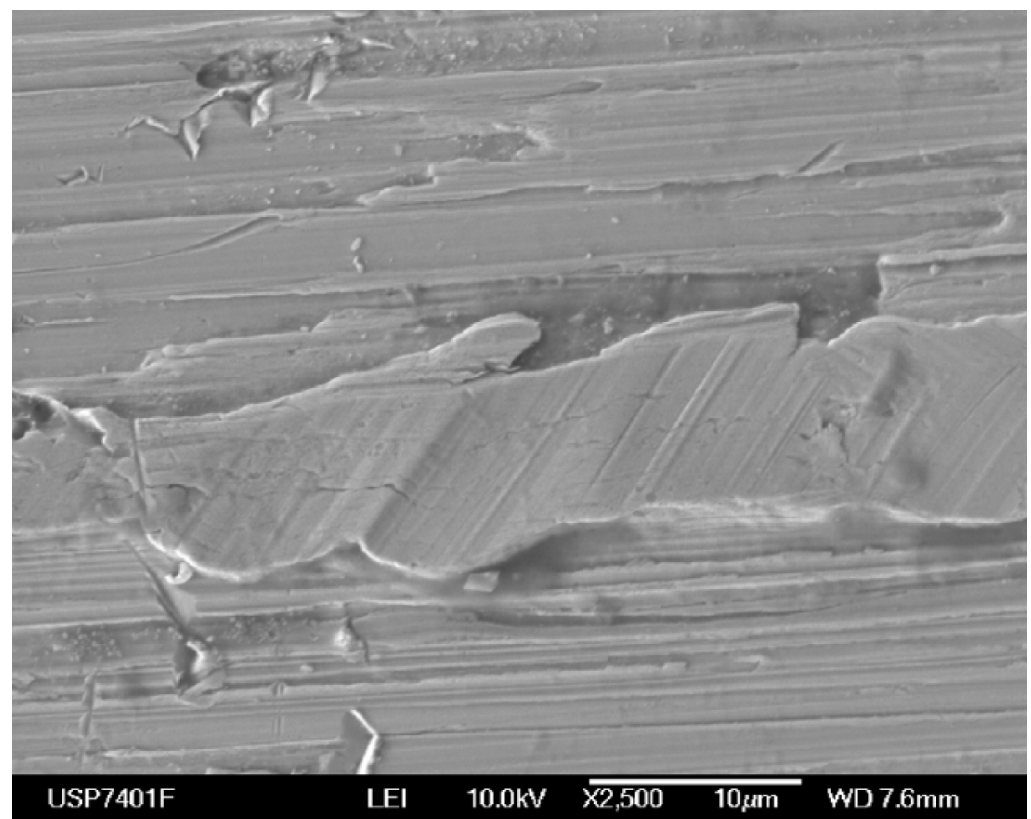

Figura 3S. Micrografia eletrônica de varredura obtida para camada de inibidor adsorvida sobre lâmina de $\mathrm{Si} / \mathrm{SiO}$, a $_{60} \pm 2{ }^{\circ} \mathrm{C}$ e na concentração de 4 v/v\%

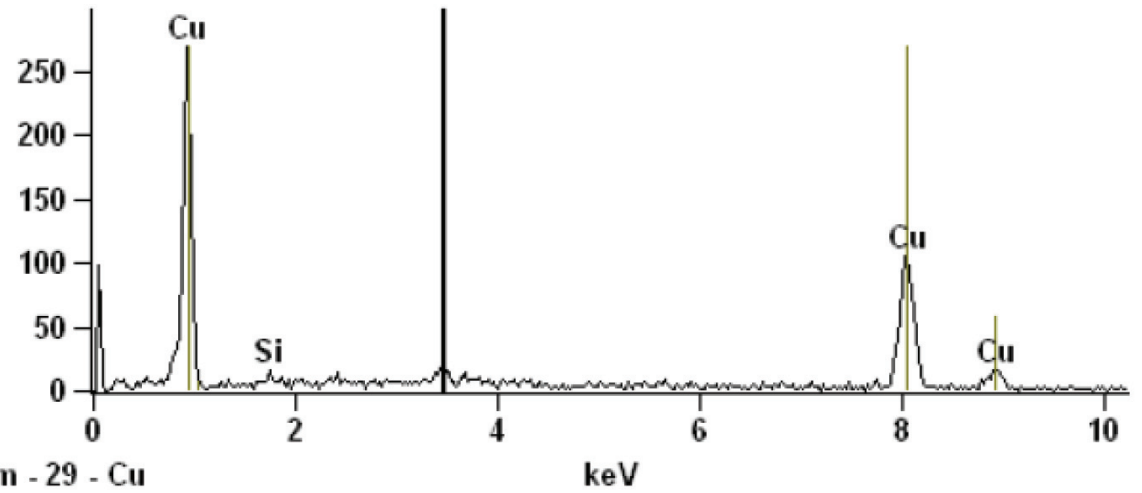

Figura 4S. Análise de EDS obtida para camada de inibidor adsorvida sobre lâmina de $\mathrm{Si} / \mathrm{SiO}$, a $60 \pm 2{ }^{\circ} \mathrm{C}$ e na concentração de $4 \mathrm{v} / v \%$

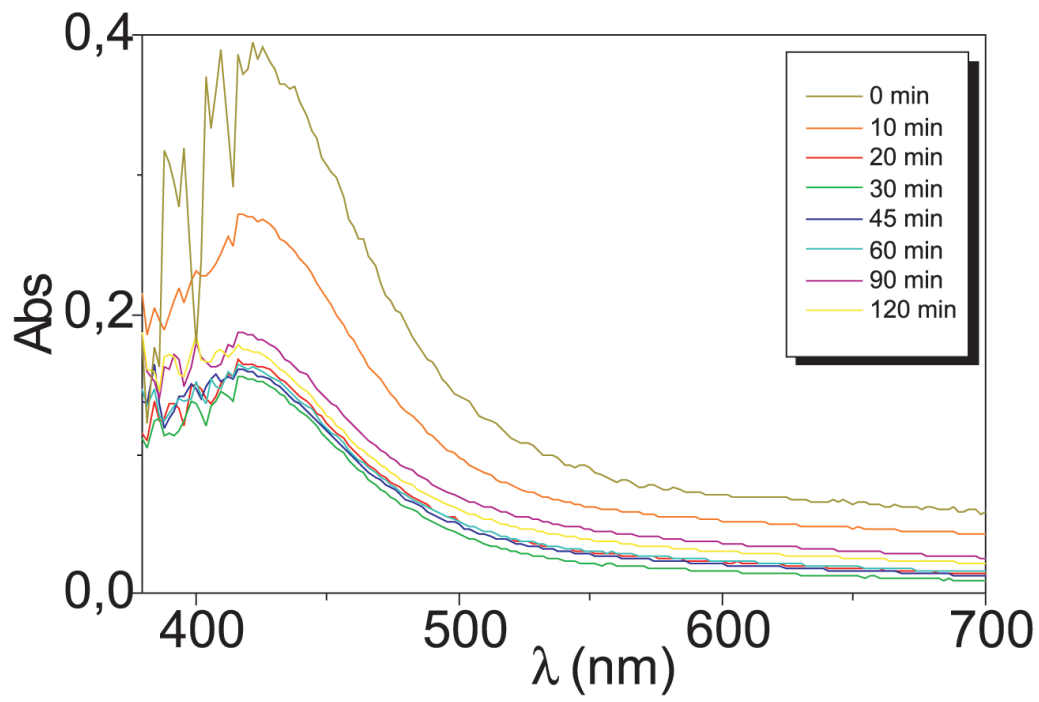

Figura 5S. Espectros de absorbância na faixa de 380 a 700 nm obtidos para as soluções sobrenadantes (diluídos 100 vezes) depois da adsorção das formulações $\mathrm{HCl} 15 \%$ sobre arenito. Cada curva representa um período de adsorção 


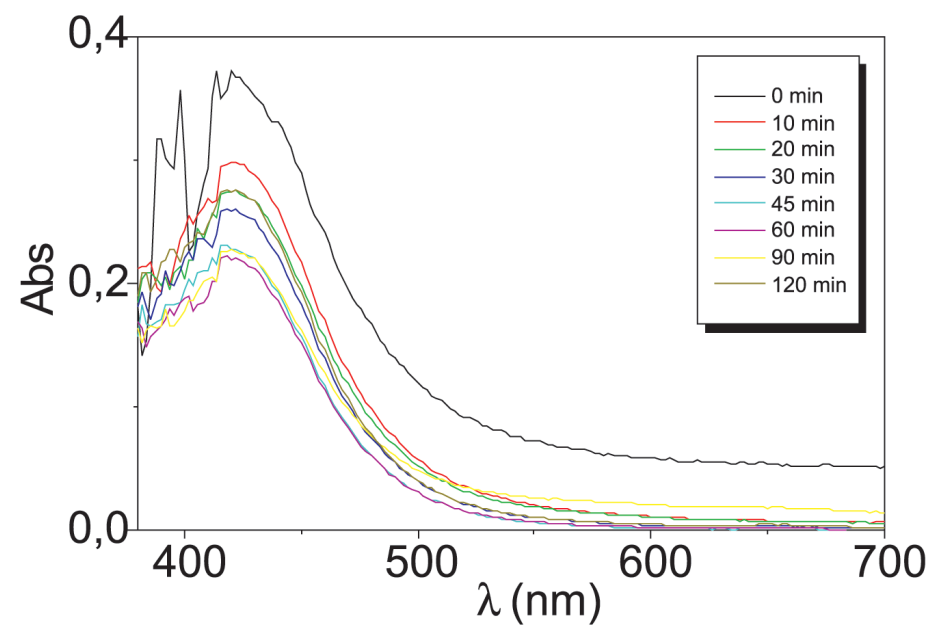

Figura 6S. Espectros de absorbância na faixa de 380 a 700 nm obtidos para as soluções sobrenadantes (diluídos 100 vezes) depois da adsorção das formulações $\mathrm{HCl}$ 13,5\% sobre arenito. Cada curva representa um período de adsorção

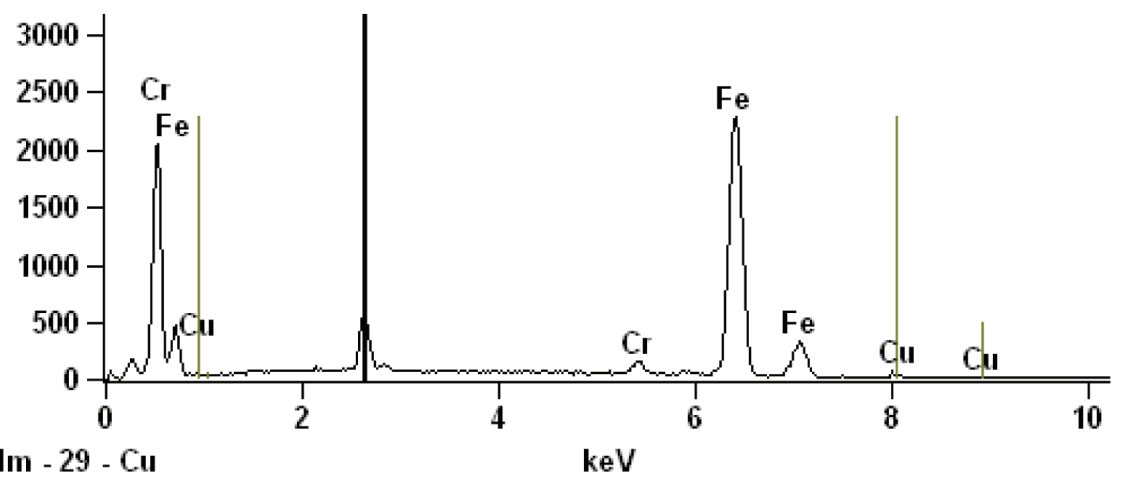

Figura 7S. Análise de EDS obtida para formulação $\mathrm{HCl} 15 \%$ adsorvida sobre aço.

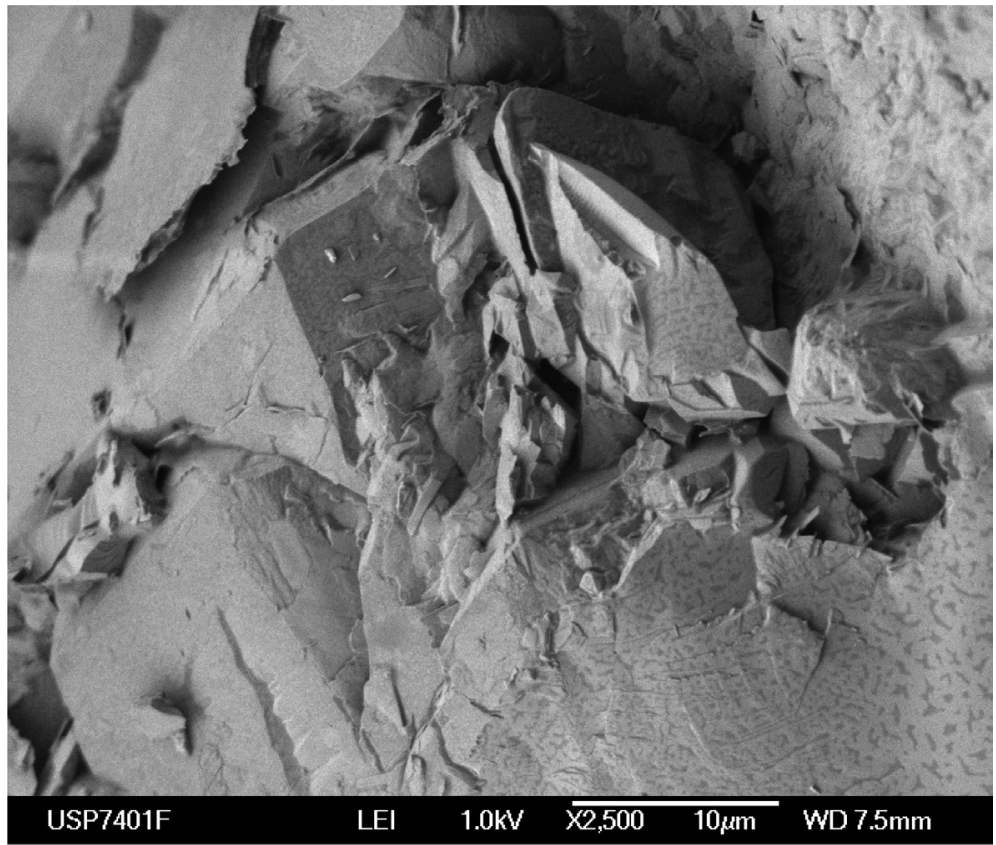

Figura 8S. Micrografia eletrônica de varredura obtida para formulações $\mathrm{HCl} 15 \%$ adsorvidas sobre arenito durante $10 \mathrm{~min}$ 


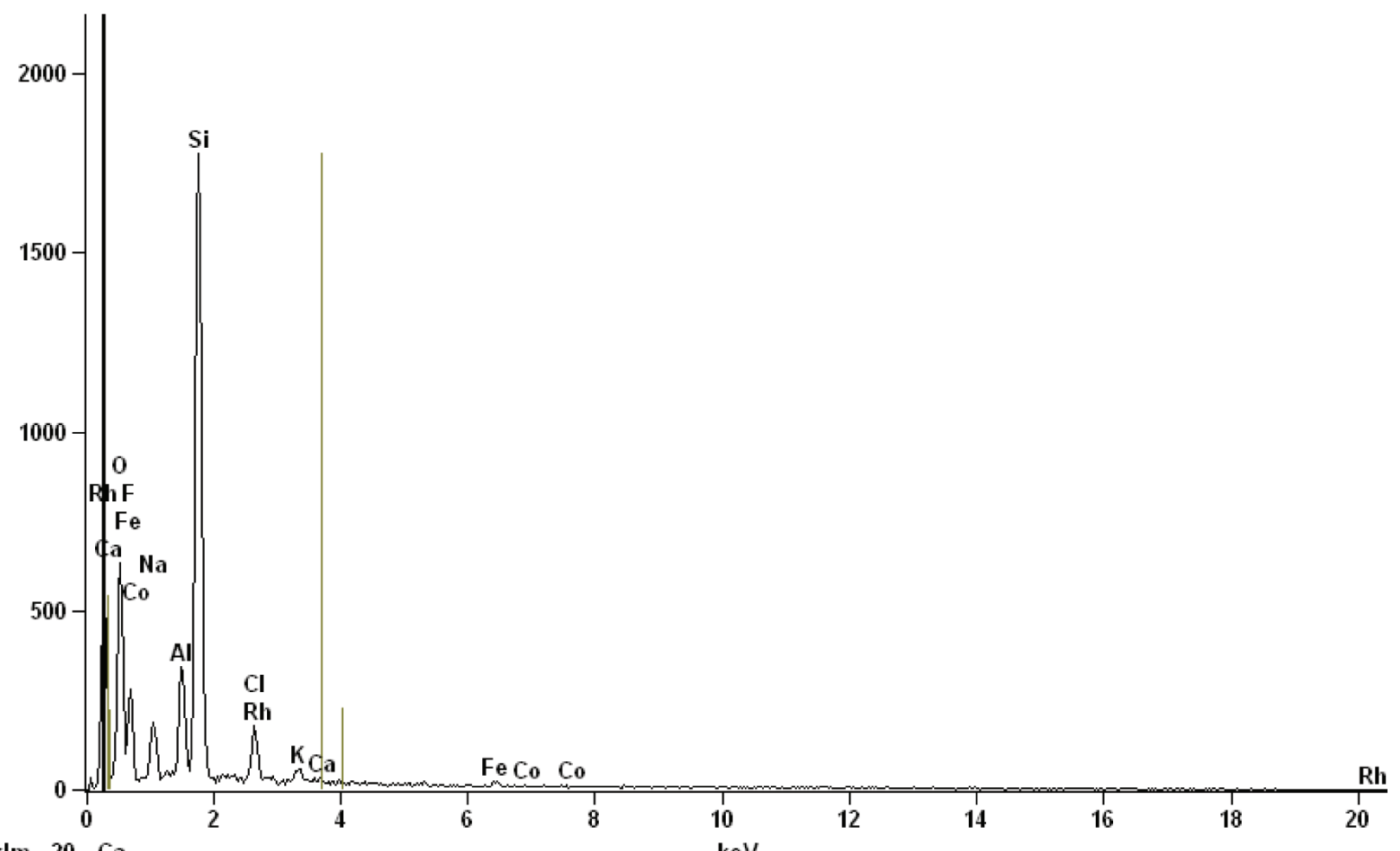

klm - 20 - Ca

Figura 9S. Análise de EDS obtida para camada adsorvida de formulação $\mathrm{HCl} 13,5 \%$ adsorvida sobre arenito durante $10 \mathrm{~min}$

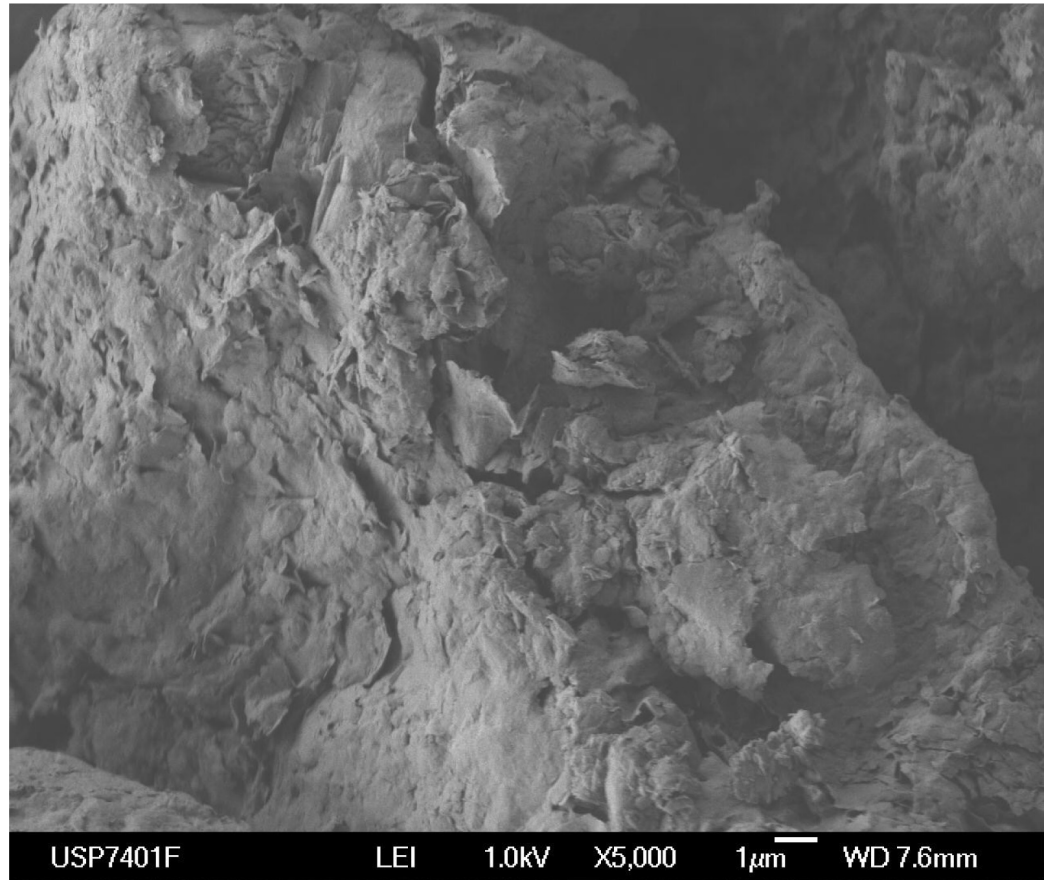

Figura 10S. Típica imagem de MEV obtida para formulações $\mathrm{HCl} 15 \%$ adsorvidas sobre esmectita durante $10 \mathrm{~min}$ 


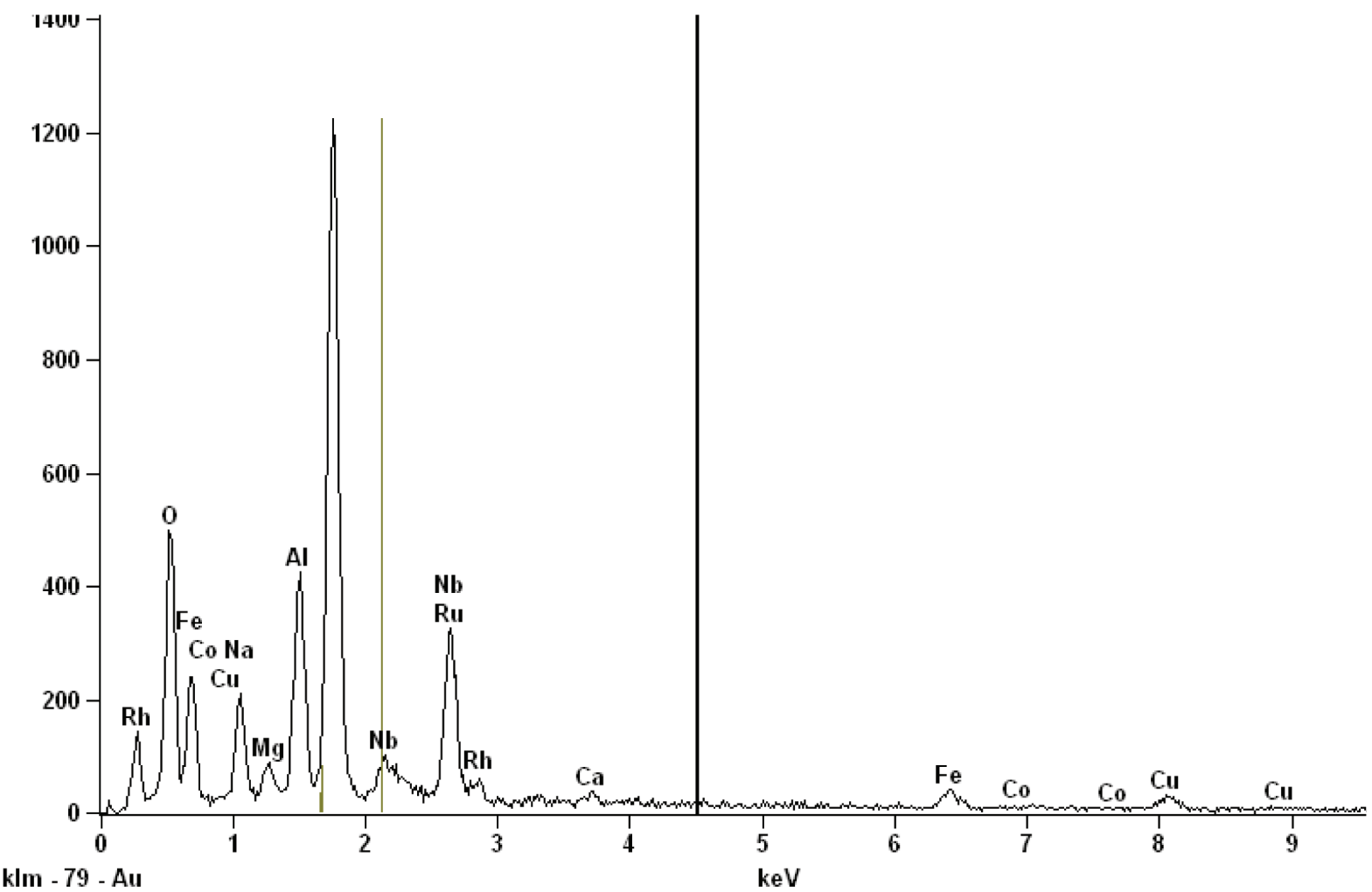

Figura 11S. Análise de EDS obtida para camada adsorvida de formulação $\mathrm{HCl}$ 13,5\% adsorvida sobre esmectita durante 10 min 